\title{
Integrative developmental ecology: a review of density-dependent effects on life-history traits and host-microbe interactions in non-social holometabolous insects
}

\author{
Anh The Than $^{1,2} \cdot$ Fleur Ponton $^{1} \cdot$ Juliano Morimoto $^{3}$ (D)
}

Received: 18 February 2020 / Accepted: 24 August 2020 / Published online: 2 September 2020

(C) The Author(s) 2020

\begin{abstract}
Population density modulates a wide range of eco-evolutionary processes including interand intra-specific competition, fitness and population dynamics. In holometabolous insects, the larval stage is particularly susceptible to density-dependent effects because the larva is the resource-acquiring stage. Larval density-dependent effects can modulate the expression of life-history traits not only in the larval and adult stages but also downstream for population dynamics and evolution. Better understanding the scope and generality of densitydependent effects on life-history traits of current and future generations can provide useful knowledge for both theory and experiments in developmental ecology. Here, we review the literature on larval density-dependent effects on fitness of non-social holometabolous insects. First, we provide a functional definition of density to navigate the terminology in the literature. We then classify the biological levels upon which larval density-dependent effects can be observed followed by a review of the literature produced over the past decades across major non-social holometabolous groups. Next, we argue that host-microbe interactions are yet an overlooked biological level susceptible to density-dependent effects and propose a conceptual model to explain how density-dependent effects on host-microbe interactions can modulate density-dependent fitness curves. In summary, this review provides an integrative framework of density-dependent effects across biological levels which can be used to guide future research in the field of ecology and evolution.
\end{abstract}

Keywords Niche theory $\cdot$ Ecological specialisation $\cdot$ Ecological theory $\cdot$ Population density $\cdot$ Microbiome $\cdot$ Host-microbiome interaction

Juliano Morimoto

juliano.morimoto@abdn.ac.uk

1 Department of Biological Sciences, Macquarie University, Sydney, NSW 2109, Australia

2 Department of Entomology, Vietnam National University of Agriculture, Trau Quy, Gia Lam, Hanoi, Vietnam

3 School of Biological Sciences, University of Aberdeen, Zoology Building, Tillydrone Ave, Aberdeen AB24 2TZ, UK 


\section{Introduction}

Population density is a key factor affecting life-history trait expression and trade-offs (Mueller et al. 1991). Individuals from low-density populations often display higher expression of fitness-related traits (e.g., higher fecundity, larger size) compared to individuals from high-density populations (Dey and Joshi 2018; Prasad and Joshi 2003). This is because high-density increases intraspecific competition which limits per capita resource acquisition (Klepsatel et al. 2018). On the other hand, social interactions may benefit individuals through cooperative feeding (Denno and Benrey 1997), predator defence (Breviglieri and Romero 2019), or potentially by sharing beneficial microbial communities that are horizontally transmitted between individuals in the group (idea developed in this paper).

Early life conditions influence fitness traits and life-history trade-offs (Nijhout 2015; Stearns 1982). As a result, early life conditions can induce long-lasting effects on fitness and population dynamics, shaping populations' evolutionary trajectories, species distribution range and extinction risks (Criscuolo et al. 2008; Lindström 1999; Monaghan 2008). In insects, population density at larval stage modulates resource availability during development that can have both negative and positive effects on development and fitness (Applebaum and Heifetz 1999). In non-social holometabolous insects in particular, competition for resources at the larval stage is known to underpin changes in larval growth as well as adult morphology and fitness (Yang 2001). Adults have limited scope to compensate for poor developmental conditions later in life, particularly in traits such as body size because adults do not moult (Belles 2011). Therefore, the larval stage is paramount for resource acquisition, with density-dependent effects being particularly notable. Interestingly, population density at the larval stage can lead to faster adaptation to novel resources through increased intraspecific competition (Bolnick 2001), a factor that can increase the ability of populations to adapt to changing environments as well as population range shifts (Lawrence et al. 2012). Thus, the implications of density-dependent effects during development are many. Yet, we still do not have a deep understanding of the far-reaching effects of early life conditions on individual life-history traits (Lindström 1999). For instance, we still do not know whether responses to high population densities are conserved across taxa or to what extent population density during development has carry-over effects to adulthood and offspring that mediate eco-evolutionary processes. As a result, we lack a generalised understanding of density-dependent effects of larval stage on life-history traits expression, tradeoffs and population dynamics (Applebaum and Heifetz 1999). This is likely a product of (1) the lack of a functionally consistent definition of density and (2) the absence of a taxonomically diverse perspective about density-dependent effects on life history. With the current decline in insect biodiversity - where the most affected insect species are holometabolous - gaining a better understanding of how different taxa respond to density-dependent conditions during development can provide important knowledge of species' life-histories that might be useful for population forecasts and conservation (Kunin 2019; Rada et al. 2019; Wagner 2019; Welti et al. 2020).

Here, we reviewed the literature on the plastic and evolutionary effects of population density at larval stage on life-history trait expression in non-social holometabolous insects. First, we provide a functional definition of density aimed to standardise the terminology used in density-dependent studies-for our own reference while writing the review and also for future studies, where a functional definition of density will allow for comparative analysis across taxa. Next, we identify the biological levels at which density-dependent 
effects are manifested in non-social holometabolous insects and review the empirical evidences underpinning density-dependent effects on the larvae (density-dependent immediate effects), adults (density-dependent delayed effects), as well as populations (densitydependent ecological effects) and across generations (density-dependent evolutionary effects) (Agnew et al. 2000; Bhavanam and Trewick 2017; Couret et al. 2014; Creland et al. 1986; Gimnig et al. 2002; Hawley 1985; Morimoto et al. 2019a; Morimoto et al. 2017a). We then discuss recent evidences that density-dependent effects could affect the interactions between the host and its microbial community (density-dependent microbial interactions) and conclude by proposing a conceptual model to explain how density-dependent host-microbial interactions can modulate the strength of density-dependent effects across biological levels. We focused on non-social holometabolous insects as sociality adds an additional layer of complexity that is beyond the scope of this review. Overall, this review aims to guide and stimulate future research within an integrated framework of insect developmental ecology [see also (Mueller 1997) for a historical review in the topic and (Applebaum and Heifetz 1999; Stiling 1988) for reviews of density-dependence in other contexts].

\section{How did we define density?}

The literature of density-dependent effects in holometabolous insects is a fruitful ground for terms referring to population density, including (but not limited to) 'low and high density' [e.g., (Henry et al. 2020; Ower and Juliano 2019)], 'aggregation' (Inouye and Johnson 2005; Morimoto et al. 2018), 'crowding' [e.g. (Lushchak et al. 2019; Morimoto et al. 2019a)] and 'overcrowding' (Ikeshoji and Mullai 1970; Roberts 1998) (the authors are themselves guilty of contributing to such panacea of terms). All of these terms capture the idea that in one treatment or condition, there are more individuals per unit of resource compared with another treatment or condition. However, the multiplicity of terms precludes appropriate comparisons of effect sizes within and between taxa. Questions such as 'is high density equivalent to crowding or overcrowding, or both?' and 'what is the difference between the levels of crowding across species (e.g., maggots vs. caterpillars)?' are highly-species and context-dependent.

Ideally, the terminology should reflect changes in density relative to the natural history of a species [see also (Travis 2020) for an appeal to natural history] but this is not always possible. The terminology is important because the effects of density can vary greatly even with small differences in experimental design for the same species [see e.g., (Mueller et al. 1993; Roper et al. 1996)] and thus a 'ruler' can help estimate and compare densitydependent effects and gain insights across taxa. In this Review, where we had to navigate through existing terminology, we opted to define density in a broad sense which allowed for general patterns of 'low' and 'high' density conditions across species to be derived (for consistency, we refer to different densities as low and high densities throughout the paper). In particular, we refer to low density treatments that include anything from one to few individuals whereas high density treatment includes large groups, aggregates and overcrowded conditions (Fig. 1a). This coercion should be taken with caution, but this broad definition allowed us to draw general conclusions. Note that our functional terminology does not attempt to provide the solution for the issue of defining low versus high density for each species and context. Nonetheless, this definition could potentially be adopted more widely in studies of density-dependent effects in insects; terminology is certainly an area for further improvements in the field. 


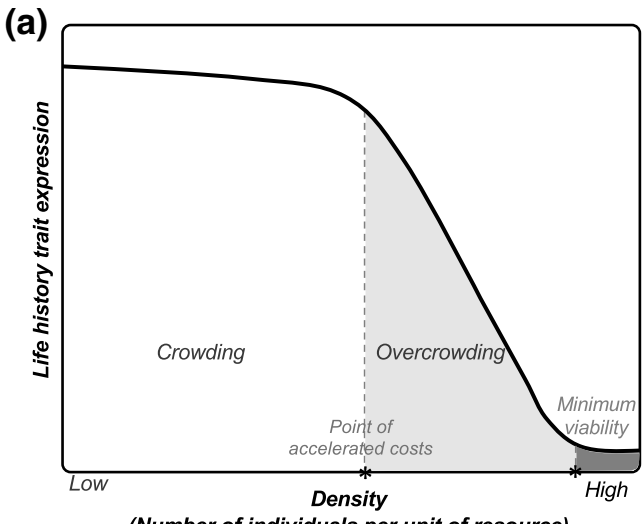

(b)

(Number of individuals per unit of resource)

Biological levels of density-dependent effects

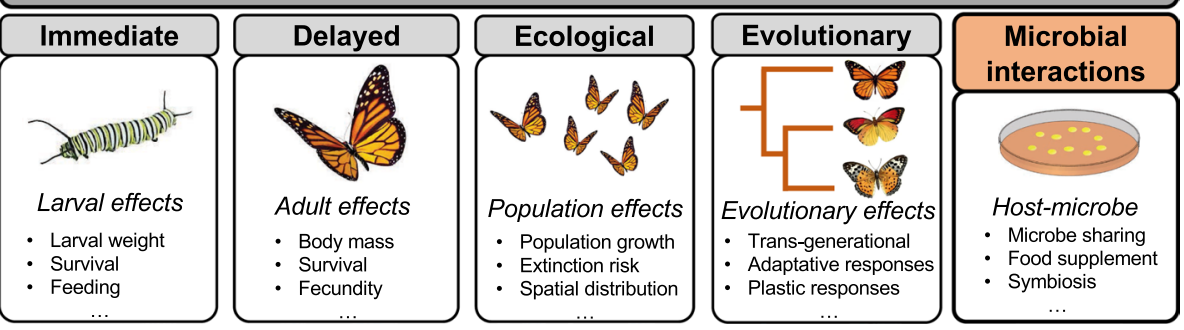

Fig. 1 Density-dependent effects across biological levels. a A simple functional definition for the terminology of density in insects. We considered low density studies that investigated single individuals (in butterflies) or small groups (in flies) and high density, studies that investigated large groups, crowding and overcrowding conditions. Note that low and high density are relative to each other and to the study species (i.e., low density in caterpillars is different from low density in maggots). This classification was necessary to conciliate the variety of terms used in density-dependent literature in ways that general insights could be obtained. We propose that, if this terminology is used more widely, crowding should reflect changes in density up to the point where the costs of density on life-history trait accelerates. For higher densities (overcrowding; light grey shaded region), the expression of life-history traits is expected to reach a minimum viable level, after which life-history trait expression does not decrease due to selection (dark grey shaded region). b The biological levels of density-dependent effects

\section{Multiple biological levels of density-dependent effects}

Density-dependent effects are observed at multiple biological levels. Here, based on a previous framework (Mueller 1997), we classified these levels as (Fig. 1b):

1. Immediate density-dependent effects, which refers to density-dependent effects that occur at the same stage at which population density is sensed. For instance, density-dependent effects on larval traits in response to larval density.

2. Delayed density-dependent effects, which refers to effects at future life stages in the response to the developmental population density. For instance, density-dependent effects on adult traits in response to larval density.

3. Ecological density-dependent effects, which refer to the density-dependent effects at the population level as a result of immediate and delayed density-dependent effects. For 
instance, changes in social interactions between individuals of a population in response to density.

4. Evolutionary density-dependent effects, which refer to density-dependent adaptations and trans-generational effects, emerging from the combination of effects in previous biological levels. For instance, density-dependent effects on offspring traits in response to parents' density.

At each biological level, the mechanisms underpinning the density-dependent effects likely vary. For example, immediate density-dependent effects are likely a result of resource acquisition and direct intraspecific competition, delayed density-dependent effects result of resource allocation trade-offs and plasticity, and evolutionary density-dependent effects is a combination of plasticity (within-generations) and evolutionary history (between generations). This classification allowed us to organise the evidence gathered here, providing a starting-point for interpreting density-dependent effects across taxa with appropriate speculation of the underlying mechanisms. Finally, we will define an additional biological level, host-microbe interactions, subject to density-dependent effects (Fig. 1b). Note that this classification does not preclude the density-dependent effects of one level to influence another (e.g., density-dependent effects on individual reproduction affects population growth and vice versa), but it allows for the formulation of clear expectation of processes leading to density-dependent effects.

\section{Density-dependent effects on life-history traits}

\section{Immediate and delayed density-dependent effects}

Immediate and delayed plastic responses to density determine individual fitness and are the roots of long-term density-dependent effects. In general, increasing larval density strengthen life-history trade-offs and lead to longer larval developmental time (but see section on eco-evolutionary adaptations below), lower adult body mass and reproductive success, as well as both larval and adult survival. For instance, in mosquitoes and flies, high larval density increases developmental time [flies: D. melanogaster and Ceratitis capitata; (Diamantidis et al. 2019; Henry et al. 2018); mosquitoes: Ae. aegypti and A. gambiae; (Agnew et al. 2002; Couret et al. 2014; Gimnig et al. 2002; Muriu et al. 2013)]. In addition, high larval density also decreases larval and adult body mass and reproductive success [flies: D. melanogaster and B. tryoni (Diamantidis et al. 2019; Morimoto et al. 2016, 2017a, 2019a); mosquitoes: Ae. aegypti, Ae. Albopictus, A. gambiae and Culex quinquefasciatus; (Agnew et al. 2000; Davis et al. 2016; Gimnig et al. 2002; Maciá 2017; Manorenjitha and Zairi 2012)] as well as larval and adult survival [flies: Drosophila willistoni and C. capitata (Baldal et al. 2005; Diamantidis et al. 2019; Dukas et al. 2001; Pearl et al. 1927); mosquitoes: Ae. aegypti, A. gambiae and C. quinquefasciatus (Agnew et al. 2000, 2002; Jannat and Roitberg 2013)]. However, adult survival was not affected by larval density in Ae. albopictus or Ae. sierrensis (Hawley 1985; Reiskind and Lounibos 2009) and high larval density increases larval survival in experimental evolution $D$. melanogaster lines [e.g., (Shenoi et al. 2016a)] at the expense of energy efficiency (Mueller 1990, 1997). High larval density also leads to an increase in adult lipid storage in D. melanogaster (Zwaan et al. 1991)] but a decrease in adult lipid storage in B. tryoni (Morimoto et al. 2019a) even in sugar-rich diets (Nguyen et al. 2019). Moreover, high larval density 
increases local temperature (Appleby and Credland 2007) and promotes a generalised stress response which can mediate individual's thermotolerance (Henry et al. 2018). Given the ongoing environmental changes and the rapid decline in insect species worldwide (Wilson and Maclean 2011), it is appealing that population density could mediate the ability of populations to overcome extreme temperature shocks (Lushchak et al. 2019). Similar general effects of larval density are observed in Hymenopterans (Kuno 1962; Milonas 2005; Taylor 1988) although more studies in parasitoids, which poses a more complex relationship between developmental density and resource (e.g., host size), are needed.

Despite the general trends described above, some fly species benefit from high density via faster developmental pace. For instance, high larval density in some blowfly and fruit fly species can lead to benefits of group feeding that shortens developmental time [e.g., Calliphora vicina (Saunders and Bee 2013); Phormia regina (Green et al. 2002); B. tryoni (Morimoto et al. 2018). In blowflies in particular, shorter developmental time in high larval densities is likely an evolutionary response to the nutritional ecology of Calliphoridae species which feed on carcass, an ephemeral resource attractive to many species. High larval density could signal to the larva that the resource is likely to become fully depleted in a shorter period of time due to intra- and inter-specific competition, thereby accelerating larval development (Reis et al. 1999). Nonetheless, these species still respond to high larval densities by developing into smaller pupae and adults [C. vicina and C. vomitoria (Ireland and Turner 2006; Saunders et al. 1999)] and having lower adult reproductive success [ $C$. vicina (Fantinou et al. 2008)].

In Coleoptera and Lepidoptera, the responses to larval density are less consistent across taxa with some species displaying positive and others negative responses to larval density. For example, some species respond to increased larval density by increasing the number of larval moults and delaying development [i.e., Lepidoptera: Pararge aegeria and Sesamia nonagrioides (Fantinou et al. 2008; Gibbs et al. 2004); Coleoptera: Zophobas atratus (Quennedey et al. 1995)], other species maintain the same [Tenebrio molitor; (Connat et al. 1991; Weaver and McFarlane 1990)] or even display faster development with increasing larval densities [Lepidoptera: Bicyclus anynana (Bauerfeind and Fischer 2005) and Chiasma clathrata (Välimäki et al. 2013)]. High larval densities can have negative [butterfly: Pieris napi (Kivelä and Välimäki 2008)] or positive effect on larval survival by increasing larval feeding efficiency ['feeding facilitation' (Nahrung et al. 2001)] and group anti-predatory defence [e.g., (Aukema and Raffa 2004)]. For instance, in burying beetles Nicrophorus vespilloides, a species where adults display parental care for the larvae, larval density facilitates feeding depending on the level of parental care. In the presence of parental care, there is a negative relationship between larval density and larval mass, likely due to increased larval competition. In the absence of parental care, there is a quadratic relationship, with larval mass being maximised at intermediate larval densities because groups of larvae could better penetrate the carcass upon which they were feeding (Schrader et al. 2015). Feeding facilitation also increased larval survival in the butterfly Chlosyne lacinia (Clark and Faeth 1997). In the moth Hylesia nigricans, high larval density allow for groups to display longer anti-predatory responses when exposed to acoustic stimuli from predators (Breviglieri and Romero 2019), a behaviour that likely increase individual and group survival probabilities. In first instar larvae of the mountain pine beetle Dendroctonus ponderosae (Cole 1973) and the eucalypt-feeding beetle Chrysophtharta Agricola, high larval density also result in higher larval survival likely due to the combination of both feeding facilitation and anti-predatory responses (Nahrung et al. 2001).

Another way in which larval density can exert positive effects on Lepidoptera and Coleoptera larvae (and potentially in other insect orders) is by increasing immune function 
(known as 'density-dependent prophylaxis') which increases resistance against parasites as well as bacterial and viral infections (Barnes and Siva-Jothy 2000; Cotter et al. 2004; Wilson and Cotter 2008; Wilson and Graham 2015) [but see (Piesk et al. 2013) for contrary evidence in $P$. napi]. Nonetheless, increasing larval density still lead to lower adult body mass survival in both Coleoptera and Lepidoptera [Lepidoptera: Elachista sp, Cnaphalocrocis medinalis, Plodia interpunctella, S. nonagrioides, Lymantria dispar, P. aegeria and Chiasma clathrata (Dai et al. 2019; Fantinou et al. 2008; Gage 1995; Gibbs et al. 2004; Lazarevic et al. 2004; Reilly and Hajek 2007; Välimäki et al. 2013); Coleoptera: Callosobruchus maculatus, O. sulcatus and Gnathocerus cornutus (Clark et al. 2011; Creland et al. 1986; Savvidou and Bell 1994; Smallegange and Tregenza 2008; Tsuda and Yoshida 1985)]. These discrepancies likely emerge through the combination of species-specific responses to density as well as experimental design.

Density-dependence can be a signal to the level of competition individuals are likely to encounter in the future. Thus, immediate and delayed plastic responses to population density are thought to represent ways through which individuals attempt to maximise fitness given the level of expected competition in the population. For instance, $D$. melanogaster males raised in high density evolve higher courtship rates (Shenoi et al. 2016b) and invest relatively more in ejaculates relative to their body mass compared with males from low density larval environments (Wigby et al. 2016) although they do not increase the expression levels of seminal proteins (McGraw et al. 2007). These plastic responses can be tailored to maximise fitness in habitats where population density is high and sperm competition is likely, although males from high larval density have lower fertilization success in general (Morimoto et al. 2016, 2017a). Males of the armyworm Mythimna separata (aka Pseudaletia separata) from high larval have significantly more apyrene (non-fertilising) sperm than males from solitary larval environments, but with no differences in eupyrene (fertilising) sperm (He and Miyata 1997). While apyrene sperm is not capable of fertilising eggs it may nonetheless affect egg fertilisation in sperm competitive contexts (Silberglied et al. 1984; Watanabe 2016). Similarly, in the gum-leaf skeletonizer moth Uraga lugens, males from high larval densities invest more in testis size but have relatively shorter wing and antenna length, revealing a tradeoff between investing in finding mates versus winning paternity (Johnson et al. 2017). Female antenna and wing sizes are density-independent or social-dependent, respectively, which uncovers sex-specific responses to population density at the larval stage (Johnson et al. 2017). In the moth $P$. interpunctella, males from high larval density emerge with relatively larger abdomens, testis, and with greater number of sperm when reared in high density conditions (Gage 1995), which can be interpreted as an adaptation to higher sperm competition in high-density population (Gage 1995). Experimental evolution in $P$. interpunctella also revealed that males evolving in low (not high) larval density transfer overall more sperm and both sexes invest less in immunity (McNamara and Simmons 2017), contradicting the predictions of standard density-dependent theory and density-dependent prophylaxis (see above). Interestingly, high larval density compounded with food shortage leads to plastic phenotypic adaptions in the adult of the flour moth Ephestia kuehniella whereby males have lower body weight but disproportionately longer wings which could facilitate migration (Bhavanam and Trewick 2017). Whether or not migratory individuals have higher fitness remains to be tested (Stamps 2006). From a spatial perspective, high larval density in the caddisfly Cheumatopsyche $s p$. (Trichoptera) leads to homogenous distribution of individuals in space, where some individuals are displaced to the edge of the group in poor habitats (Glass and Bovbjerg 1969). Displaced individuals might experience poorer environments and emerge 
as adults that are prone to dispersal, thereby influencing population range distribution (Dethier 1959) as well as generating spatial sorting of genotypes that can lead to spatial evolution (Shine et al. 2011) (Fig. 2a). This remains untested but is an important topic for future studies. Lastly, it is important to mention that low larval density is positively associated with direct development rather than diapause in the butterfly $C$. clathrata (Välimäki et al. 2013), suggesting that larval density can also modulate modes of development. More studies are needed in this area.

(a)

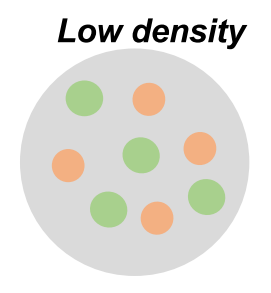

\section{Genotype A}

Genotype B

(c)

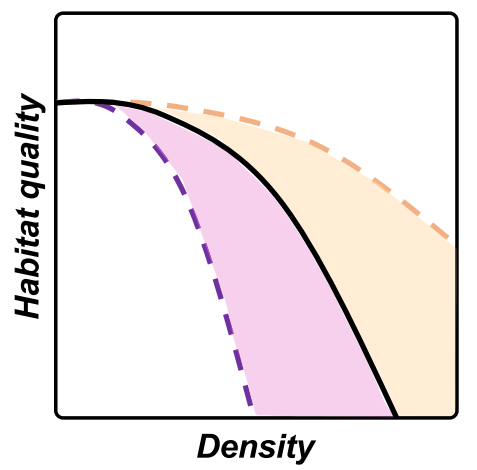

(b)

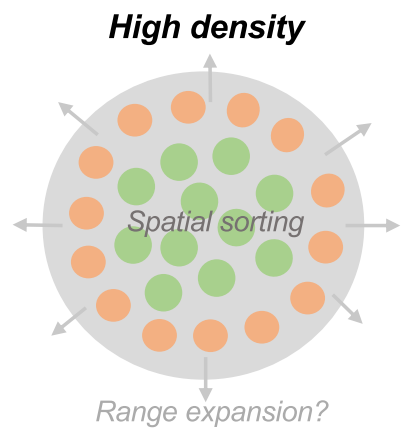

(d)

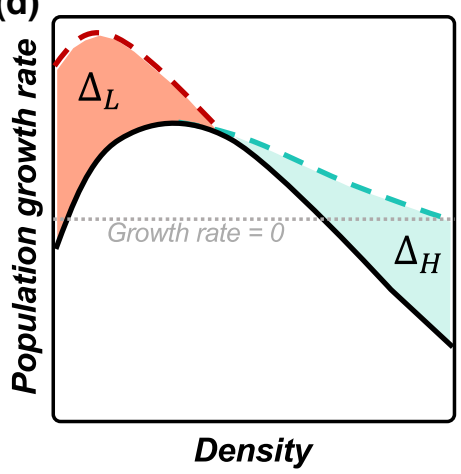

Fig. 2 Population density, spatial sorting and density-dependent effects on host-microbe interactions. a High larval densities may displace individuals (and consequently, their genotypes) towards the periphery of the population. These individuals at the periphery might be more prone to migrate (either as a response to density per se or as a result of other factors [e.g., interactions between density and nutrition; see main text]. This can in theory contribute to population range expansion and spatial evolution. b Density-dependent host-microbe interactions can generate the potential for accelerated or decelerated growth rates during larval development. As a result, maximum growth rate might be achieved faster or slower depending on the population density and the microbial community present in the environment. Changes in maximum growth rate are not displayed here but are nevertheless possible. c As microbes can serve as food, host-microbe interaction can modulate the rate of habitat degradation by population density. Scenarios where microbes increase (orange) or decrease (pink) environmental quality are shown. d At the population level, densitydependent host-microbe interactions can mediate population growth rates. For example, population growth rates may increase in low (red) or high (turquoise) densities due to the sum of the density-dependent effects on host-microbe interactions at the individual level 


\section{Ecological and evolutionary density-dependent effects}

Larval density-dependent effects can modulate how a species interact with itself (e.g., intraspecific competition) and with other species (e.g., predators, preys), or both [e.g., (Arditi et al. 2001; May et al. 1981) This will determine both the ecological significance of the species within the ecosystem (ecological density-dependent effects) as well as the evolutionary trajectory of the species over generations (evolutionary density-dependent effects) [e.g., (Cappuccino 1992; Hassell and May 1986; Liu et al. 2007).

Many insights into within-species ecological and evolutionary density-dependent effects emerged from studies in Drosophila (Mueller 1997). For instance, D. melanogaster populations evolved at high larval densities displayed increased population growth rates, which is the opposite pattern observed for populations evolving at low densities that evolved reduced population growth rates. (Mueller and Ayala 1981; Mueller et al. 1991); this is evidence for the evolution of increased population carryingcapacity at high population densities. In addition, D. melanogaster larval feeding rates (a measure of larval competitive ability), cannibalism, and ability to withstand toxic waste (i.e., ammonia and urea) also increase (although not for all species) in populations experiencing or evolving high larval densities [(Belloni et al. 2018; Borash et al. 1998; Borash and Shimada 2001; Vijendravarma et al. 2013); see also review in (Joshi et al. 2001)], albeit creating a trade-off with larval energy efficiency (Joshi and Mueller 1996; Joshi et al. 2001; Mueller 1990). However, this trade-off is not necessarily observed in other Drosophila species (Nagarajan et al. 2016) suggesting that the natural history of species may lead to different responses to population density. Interestingly, even within a single cohort of individuals in a high-density population, density-dependent effects generate and maintain genetic polymorphism. This is because individuals that develop faster (early developers) have higher feeding rates but lower viability and tolerance to toxic waste compared with individuals that develop later (late developers) (Borash et al. 1998). Furthermore, density-dependent selection also leads to differential allelic composition for a single locus foraging (for) gene, corroborating that high population density can maintain genetic polymorphism in populations (Sokolowski et al. 1997). Population density at the larval stage also mediates plastic reproductive strategy responses at the population level which ultimately affects population survival and growth. For example, D. melanogaster populations with individuals raised in high larval density have significantly faster reproductive rates but lower survival than populations with individuals from low larval density or populations with mixed compositions (low and high larval density individuals) (Morimoto et al. 2016, 2017a). Such changes in reproductive rate also lead to changes in sexual selection and sexual conflict (Morimoto et al. 2016, 2017a) [see also (Prasad et al. 2001)]. In addition, parental larval density can affect offspring body mass, opening up the potential for long-term trans-generational effects of larval density (Morimoto et al. 2017a).

Although relatively less common, studies in other species have allowed us to gain insights into both within- and between-species density-dependent effects of larval density. For instance, previous studies have shown that when density of larvae (prey) from the shield beetle Cassida rubiginosa increased, they were more likely a preferred target for the generalist paper wasp parasitoid Polistes dominulus, which showed a type III functional response to prey density (Schenk and Bacher 2002). Moreover, higher densities of strawberry ground beetle Pterostichus melanarius larvae (predator) are more efficient at reducing biomass of two slug species (between-species density-dependent 
effects), although higher larval density also resulted in higher cannibalism rates due to stronger intraspecific competition (within-species density-dependent effects) (Thomas et al. 2009). Together though, these findings demonstrate that larval density-dependent effects have long-lasting ecological and evolutionary consequences to populations, species, and ecosystems.

\section{Host-microbe interactions as a missing factor}

Based on the evidences provided above, one could ask: why do responses to high larval density vary greatly between insect populations, species and Orders? A definite answer to this question is difficult to answer due to the lack of empirical work across taxa. While part of this emerge from differences in experimental design, it is likely that some portion of this variation in responses to larval density are rooted in differences of developmental biology processes. For instance, while Diptera, Coleoptera and Lepidoptera larvae need to reach a threshold size (critical mass) for pupation, Diptera has a fixed number of larval instars while Coleoptera and Lepidoptera larvae possess flexibility on the number of larval instars that can precede metamorphosis (Belles 2020; Mirth et al. 2005; Truman 2019). The last stages of Coleoptera and Lepidoptera larval development are particularly sensitive to nutrients, and commitment to metamorphosis can be adjusted based on environmental and nutritional conditions (Belles 2020; Truman 2019). The ecological factors that interact with population density [e.g., temperature (Pétavy et al. 1997)] can also contribute to developmental plasticity. Despite this, many ecological factors have not yet been fully integrated within the framework of density-dependent effects in developmental ecology. In the next section, we discuss recent evidence that shows that the relationship between individuals and microbes can promote developmental plasticity and enable individual development in challenging conditions. We then argue that host-microbe interactions can be an additional unit of density-dependent effects, which can mitigate or accentuate density-dependent effects across all biological levels.

\section{Interactions between host and microbes}

Microbial communities can modulate the expression of life-history traits in insects via an intricate communication network involving the immune system (Newton et al. 2013) and which, as a result, affect the expression of traits not only related to the immune system (Genta et al. 2006; Gonzalez-Ceron et al. 2003) but also to metabolism and development (Ben-Yosef et al. 2014, 2015; Morimoto et al. 2019b; Warnecke et al. 2007; Zhou et al. 2007). Microbial communities also help insect hosts overcome chemical defenses (BenYosef et al. 2015), acquire nutrients (Ben-Yosef et al. 2014; Bing et al. 2018; Sannino et al. 2018), and serve as direct source of nutrients (Nguyen et al. 2019). Furthermore, microbes also interact with insect host to modulate adult oviposition behaviour (Jose et al. 2019), foraging (Wong et al. 2017), reproductive success (Morimoto et al. 2017b) and potentially mate choice (Sharon et al. 2011) [but see (Leftwich et al. 2017)]. Microbes are therefore the 'gatekeepers of organism fitness' (Colombani and Andersen 2020).

Population density can influence host-microbe interactions directly, via horizontal transmission of strains through social interactions, or indirectly, by modulating the diversity of strains present in a given population as well as the physico-chemical conditions of the substrate for microbial growth. For instance, increased larval density is associated 
with accumulation of toxic compounds (i.e., urea, ammonia) excreted in the substrate which are known to modulate the microbial composition of the substrate [see e.g., (Henry et al. 2020)]. The underlying mechanisms remain unknown, but at higher larval densities, chemical changes (e.g., $\mathrm{pH}$ ) likely favour the growth of some microbial strains over others

(Gibson et al. 1988; Rousk et al. 2009; Russell and Dombrowski 1980). Moreover, microbial strains might interact with each other via metabolites in order to promote growth of a cohort of strains which together, influence larva's development and life history trait (Consuegra et al. 2020; Lesperance and Broderick 2020; Sommer and Newell 2019). Given that a large proportion of microbes are acquired from interactions between the host and the surrounding environment, larval density might be important, yet an overlooked factor, in modulating host-microbe interactions (Broderick et al. 2004; Colman et al. 2012; Tang et al. 2012; Vacchini et al. 2017; Yun et al. 2014; Zhang et al. 2018; Zhao et al. 2017). Below, we summarise the main consequences of host-microbe interactions (especially microbes in the gut) to insect life-history trait expression while discussing potential ways through which larval population density could influence these effects. Note that our goal was not to review the (gut) microbe literature as extensive reviews have been published elsewhere [e.g., (Bahrndorff et al. 2016; Bordenstein and Theis 2015; Douglas 2009, 2015, 2019; Lesperance and Broderick 2020; Lewis and Lizé 2015)]. Instead, our aim is to demonstrate potential links between population density and (gut) microbe effects on fitness.

\section{Density-dependent effects on host-microbe interactions and the modulation of fitness curves}

Insects depend on their microbiome for successful development which opens up the possibility for density-dependent effects to modulate host-microbe interactions in ways that benefit (or harm) individuals. We therefore propose that host-microbe interaction is an additional biological level on its own right which is subjected to density-dependent effects. For instance, the mosquitoes Ae. aegypti, A. gambiae and Georgecraigius atropalpus fail to complete larval development in the absence of commensal microbes (Coon et al. 2014; Correa et al. 2018). The developmental arrest is rescued upon reinoculation with the enterobacteria Escherichia coli into germ-free larvae (Coon et al. 2014), suggesting that host-microbe interactions drive development. Similar effects were described in the mosquito $C$. quinquefasciatus where the presence of the phosphorus-rich bacterium Pseudomonas aeruginosa increases growth rate in phosphorous-poor diet (Peck and Walton 2006) although high concentration of the phosphorus-rich bacteria inhibited the development of another mosquito, Culex tarsalis, which highlights the species-specific interactions amongst host and microbes (Peck and Walton 2006). Studies in D. melanogaster also showed that some microbial strains can decrease larval survival and adult sizes due to toxic compounds and competition for nutrients ('animal-microbe competition') [see both (Trienens et al. 2010; Wertheim et al. 2002) for similar results]. Conversely, two microbes-Lactobacillus plantarum and Acetobacter pomorum - can rescue developmental time and larval growth in nutrient-deficient diets by acting on major hormonal signalling pathways (i.e., Insulin and TOR) (Shin et al. 2011; Storelli et al. 2011, 2018; Westfall et al. 2019). Interestingly, these microbes rely on metabolites from each other to grow and to provide developmental benefits to the host (Consuegra et al. 2020; Henriques et al. 2019; Sommer and Newell 2019). In particular, a recent study has revealed that the cross-feeding between L. plantarum and $A$. pomorum is mediated by lactate, amino acids, and vitamins (e.g., biotin) which together 
promote microbial growth that stimulate the endocrine and metabolic systems of $D$. melanogaster larvae (Consuegra et al. 2020). These interactions are important because high larval density is known to decrease the availability of protein in the diet (Klepsatel et al. 2018) and the cross-talk between microbes can buffer against nutritional stress. Also, microbial strains modulate adult reproductive success and offspring body mass in D. melanogaster (Morimoto et al. 2017b), corroborating the long-lasting effects of hostmicrobe interaction. Together, these findings reveal a complex host-microbe relationship that modulates host development and fitness.

Population density can modulate the microbial diversity in the substrate as well as in the population and facilitate the horizontal transmission of microbial strains between individuals due to increased levels of social interactions. In D. melanogaster larvae from high density conditions show a trend for elevated microbial richness (Henry et al. 2020). Likewise, the diet of high density larval conditions showed significantly higher microbial richness and diversity compared to the diets of low density larval conditions (Henry et al. 2020). Microbial growth is also known to buffer against nutritional stress caused by high larval density, aiding the expression of life-history traits such as pupal weight, adult weight and to a smaller extent, lipid storage (Nguyen et al. 2019). Microbes can also be food supplements for the developing larvae and thus, an important way to modulate the strength of density-dependent effects (Augustinos et al. 2015; Drew et al. 1983; Kaznowski et al. 2005; Salem et al. 2014). Thus, microbial diversity, transmission, and host-microbe interactions are likely density-dependent.

In this study, we propose that the effects of density-dependence on host-microbe interactions can modulate the distribution of life history trait values, the shape of individual's fitness curves and ultimately, the opportunity for-and strength of - selection in populations. Using the framework proposed by (Edelaar and Bolnick 2019), we hereby describe a conceptual model of how density-dependent effects on microbe interactions can affect individual and population fitness. According to the framework in (Edelaar and Bolnick 2019), a non-stochastic Gaussian fitness curve $W_{i j}$ links trait and fitness whereby changes in individual fitness through time is given by

$$
\frac{d W_{i j}}{d t}=\frac{\partial W_{i j}}{\partial x_{i j}} \frac{\partial x_{i j}}{\partial t}+\frac{\partial W_{i j}}{\partial X_{j}} \frac{\partial X_{j}}{\partial t}+\frac{\partial W_{i j}}{\partial \omega_{j}} \frac{\partial \omega_{j}}{\partial t}+\frac{\partial W_{i j}}{\partial c_{j}} \frac{\partial c_{j}}{\partial t}
$$

[reproduced integrally here from (Edelaar and Bolnick 2019) for clarity]. $W_{i j}$ refers to the fitness of an individual $i$ in environment $j . x_{i j}$ refers to the value of trait $x$ of individual $i$ in environment $j, X_{j}$ is the optimum trait value for environment $j, \omega_{j}$ is inversely related to the strength of stabilizing selection in trait $x$ in environment $j$ and $c_{j}$ is the maximum achievable fitness for environment $j$ (Edelaar and Bolnick 2019). Below, we firstly explain the meaning of each of the terms according to (Edelaar and Bolnick 2019) followed by recent evidence which suggest that density-dependent effects can act upon each of the terms:

- $\frac{\partial W_{i j}}{\partial x_{i j}} \frac{\partial x_{i j}}{\partial t}$ represents the change in individual fitness through time via temporal changes in individual's trait value; it is subdivided into two components: constitutive growth (i.e., growth rate) and the interaction between the trait value and the environment (Edelaar and Bolnick 2019).

Density-dependent effects on host-microbe interactions can affect individual's growth rates by accelerating (or decelerating) individual's nutrients uptake as well as influencing hosts' metabolism (Fig. 2b) (Henriques et al. 2019; Jing et al. 2020; 
Morimoto et al. 2019b; Sommer and Newell 2019). Note that density-dependent effects on host-microbe interactions are likely time-dependent given that the individual, the environment and the microbes change over the developmental period of an individual, thereby influencing the nature of host-microbe interactions [e.g., (Chen et al. 2016; Johnston and Rolff 2015)].

- $\frac{\partial W_{i j}}{\partial X_{j}} \frac{\partial X_{j}}{\partial t}$ represents the change in individual's fitness through time via temporal changes in local environment optimum (e.g., social group, (micro)habitat quality) (Edelaar and Bolnick 2019).

We hypothesise that density-dependent effects on host-microbe interactions can influence how individuals interact with conspecifics. One way this could occur is if density-dependent effects on host growth (see previous paragraph) affects phenotypic variation in the host (e.g., body size) (Crespi 1989). Another way in which densitydependent effects on host-microbe interactions can modulate social networks is via uneven spatial distribution of phenotypes (+ microbes) as a result of foraging decisions and mate selection. Previous studies have shown that fruit fly larvae (and adults) prefer to feed on diets that contain similar microbes as in their guts (Wong et al. 2017) while microbes also modulate locomotor activity in adults (Schretter et al. 2018). Previous studies have shown that population density can modulate eco-evolutionary processes that influence social networks (Vander Wal and Webber 2019). Moreover, as discussed above, host-microbe interactions can affect how individuals forage (Wong et al. 2017), move (Schou et al. 2013; Schretter et al. 2018) and mate (Sharon et al. 2011). Thus, population density can modulate the strength of mate choice and foraging choices, which in turn can generate higher or lower levels of assortativity (i.e., individuals interacting with similar or dissimilar individuals) in the social network, respectively (Crespi 1989; Jiang et al. 2013). For example, low density populations can have low assortativity as individuals are required to interact (e.g., mate choice, foraging site) with conspecifics with similar and different microbial profiles. Conversely, high density populations can have high assortativity whereby individuals preferentially interact with conspecifics with similar microbial profile in 'sub-networks' within populations. The opposite prediction is also possible, namely high assortativity in low density due to the potential for more structured populations, although if this persists throughout the reproductive stage, this could incur an opportunity cost for individuals in low density populations (e.g., low mating encounter rate). Recent studies have shown that groups of adult Drosophila tend to display some level of aggregation and social interactions that are density-dependent, with social distancing determined by specific neuronal circuits activated by contact amongst individuals in the groups and cluster formation dependent upon olfactory cues (Jiang et al. 2020; Rooke et al. 2020). These evidences suggest that density-dependent effects can modulate how individuals respond to social cues, ultimately affecting the propensity of individuals to form (dis)similar clusters within the social network structure.

- $\frac{\partial W_{i j}}{\partial \omega_{j}} \frac{\partial \omega_{j}}{\partial t}$ represents the change in individuals' fitness through time via the strength of stabilising selection (Edelaar and Bolnick 2019).

Theoretical and empirical work shows that strong stabilising selection eliminate genetic variability in the population [e.g., (Barton and Keightley 2002; Brooks et al. 2005; Hunt et al. 2007; Johnson and Barton 2005)]. Density-dependent host-microbe interactions can decrease frequency of extreme phenotypes by buffering against genetic variance of the host and negative ecological or nutritional conditions [see discussion above; (Ma et al. 2019)]. This can modulate the opportunity for and potentially the 
strength of -stabilising selection in a population; a possible consequence of this process is that genetic variability in a population might be partly maintained in the population, as the frequencies of extreme phenotypes decrease due to the 'buffering' effects of host-microbe interactions.

- $\frac{\partial W_{i j}}{\partial c_{j}} \frac{\partial c_{j}}{\partial t}$ represents the change in individual fitness through time via increasing overall environmental quality (Edelaar and Bolnick 2019).

Density-dependent effect on host-microbe interactions can increase (or decrease) overall habitat quality via modulating availability of microbes as additional food source or competitors as well as the microbial diversity and horizontal transmission probabilities [see e.g., (Nguyen et al. 2019; Trienens et al. 2010; Wertheim et al. 2002)]. In fact, larval density modulates microbial composition of the substrate. The environment itself can feedback and modulate the amount of microbes and the types of host-microbe interactions during development (Zaada et al. 2019). Therefore, density-dependent effects on host-microbe interactions mediate changes in habitat quality and consequently, its carrying capacity (Fig. 2c).

The sum of density-dependent effects on microbe-host interactions at the individual level can affect population fitness and the strength of natural selection. For instance, low density populations (e.g., populations near the distribution edge), where habitat may have lower quality, can benefit from density-dependent host-microbe interactions in ways that population growth curve increases even in low densities (i.e., $\Delta_{L}$, in Fig. 2d). Likewise, high-density populations (e.g., source population in a source-sink model) can mitigate the density-dependent negative effects of a reduction in nutrient per capita by sharing microbes that can support development in challenging conditions as well as using microbes as food. This may increase carrying capacity of the habitat and decelerate the decline in population growth rates at higher densities $\left(\Delta_{H}\right.$ in Fig. 2 d). These population-level conceptual models assume that mothers lay eggs in the best resource for larval development (i.e., low mother-offspring conflict) and/or for beneficial microbial growth or transmit microbes vertically; these are somewhat realistic assumption and known to occur in insects [e.g., (García-Robledo and Horvitz 2012; Herren et al. 2013)]. Verbal models can overlook assumption that are only identified in more rigorous mathematical formulations (Mueller 1997). Thus, further theoretical and empirical work are needed to mathematically formalise this conceptual model and understand its assumptions. This conceptual model shows that density-dependent effects on host-microbe interactions can underpin changes in traditional density-dependent effects on life history traits.

\section{Conclusion}

Density-dependent effects mediate life-history trait expression and trade-offs, affecting individual fitness and population dynamics (Mueller 1997). Here, we reviewed the evidence of density-dependent effects of population density during development in holometabolous insects. We provided a functional definition of density aimed at standardizing future studies and allowing for comparative research. We then discussed recent advances in our knowledge about the host-microbe interaction and suggest that the host-microbe interaction is an additional level upon which density-dependent effects can modulate individual fitness and eco-evolutionary processes acting on populations. We are still a long way from gaining comprehensive understanding of holometabolous insects' developmental ecology. 
A more taxonomically diverse exploration of the effects of larval density on life-history traits will allow us to better understand the plasticity in response to developmental conditions and how this varies across habitats (e.g., aquatic vs. terrestrial larva).

Acknowledgements ATT was funded by MQ-VIED Joint Scholarship at Macquarie University. We would like to acknowledge two anonymous reviewers and the editor for useful comments on the early version of this manuscript and Prof N. Prasad for constructive comments during the manuscript revision.

\section{Compliance with ethical standards}

Conflict of interest The authors declare no conflict of interests.

Open Access This article is licensed under a Creative Commons Attribution 4.0 International License, which permits use, sharing, adaptation, distribution and reproduction in any medium or format, as long as you give appropriate credit to the original author(s) and the source, provide a link to the Creative Commons licence, and indicate if changes were made. The images or other third party material in this article are included in the article's Creative Commons licence, unless indicated otherwise in a credit line to the material. If material is not included in the article's Creative Commons licence and your intended use is not permitted by statutory regulation or exceeds the permitted use, you will need to obtain permission directly from the copyright holder. To view a copy of this licence, visit http://creativecommons.org/licenses/by/4.0/.

\section{References}

Agnew P, Haussy C, Michalakis Y (2000) Effects of density and larval competition on selected life history traits of Culex pipiens quinquefasciatus (Diptera: Culicidae). J Med Entomol 37:732-735

Agnew P, Hide M, Sidobre C, Michalakis Y (2002) A minimalist approach to the effects of density-dependent competition on insect life-history traits. Ecol Entomol 27:396-402

Applebaum SW, Heifetz Y (1999) Density-dependent physiological phase in insects. Annu Rev Entomol 44:317-341

Appleby JH, Credland PF (2007) The role of temperature and larval crowding in morph determination in a tropical beetle, Callosobruchus subinnotatus. J Insect Physiol 53:983-993

Arditi R, Tyutyunov Y, Morgulis A, Govorukhin V, Senina I (2001) Directed movement of predators and the emergence of density-dependence in predator-prey models. Theor Popul Biol 59:207-221

Augustinos AA, Kyritsis GA, Papadopoulos NT, Abd-Alla AMM, Cáceres C, Bourtzis K (2015) Exploitation of the Medfly gut microbiota for the enhancement of sterile insect technique: use of Enterobacter sp. in larval diet-based probiotic applications. PloS one 10:e136459

Aukema BH, Raffa KF (2004) Does aggregation benefit bark beetles by diluting predation? Links between a group-colonisation strategy and the absence of emergent multiple predator effects. Ecol Entomol 29:129-138

Bahrndorff S, Alemu T, Alemneh T, Lund Nielsen J (2016) The microbiome of animals: implications for conservation biology. Int J Genom 2016:5304028

Baldal E, van der Linde K, Van Alphen J, Brakefield P, Zwaan B (2005) The effects of larval density on adult life-history traits in three species of Drosophila. Mech Ageing Dev 126:407-416

Barnes AI, Siva-Jothy MT (2000) Density-dependent prophylaxis in the mealworm beetle Tenebrio molitor L. (Coleoptera: Tenebrionidae): cuticular melanization is an indicator of investment in immunity. Proc R Soc Lond Ser B Biol Sci 267:177-182

Barton NH, Keightley PD (2002) Understanding quantitative genetic variation. Nat Rev Genet 3:11-21

Bauerfeind SS, Fischer K (2005) Effects of food stress and density in different life stages on reproduction in a butterfly. Oikos 111:514-524

Belles X (2011) Origin and evolution of insect Metamorphosis. In: Encyclopedia of life sciences (ELS). John Wiley \& Sons, Ltd, Chichester. https://doi.org/10.1002/9780470015902.a0022854

Belles X (2020) Insect metamorphosis: from natural history to regulation of development and evolution. Academic Press, Cambridge

Belloni V, Galeazzi A, Bernini G, Mandrioli M, Versace E, Haase A (2018) Evolutionary compromises to metabolic toxins: ammonia and urea tolerance in Drosophila suzukii and Drosophila melanogaster. Physiol Behav 191:146-154 
Ben-Yosef M, Pasternak Z, Jurkevitch E, Yuval B (2014) Symbiotic bacteria enable olive flies (Bactrocera oleae) to exploit intractable sources of nitrogen. J Evol Biol 27:2695-2705

Ben-Yosef M, Pasternak Z, Jurkevitch E, Yuval B (2015) Symbiotic bacteria enable olive fly larvae to overcome host defences. R Soc Open Sci 2:150170

Bhavanam S, Trewick S (2017) Effects of larval crowding and nutrient limitation on male phenotype, reproductive investment and strategy in Ephestia kuehniella Zeller (Insecta: Lepidoptera). J Stored Prod Res 71:64-71

Bing XL, Gerlach J, Loeb G, Buchon N (2018) Nutrient-dependent impact of microbes on Drosophila suzukii development. MBio 9:e02199-02117

Bolnick DI (2001) Intraspecific competition favours niche width expansion in Drosophila melanogaster. Nature 410:463-466

Borash DJ, Shimada M (2001) Genetics of larval urea and ammonia tolerance and cross-tolerance in Drosophila melanogaster. Heredity 86:658-667

Borash DJ, Gibbs AG, Joshi A, Mueller LD (1998) A genetic polymorphism maintained by natural selection in a temporally varying environment. Am Nat 151:148-156

Bordenstein SR, Theis KR (2015) Host biology in light of the microbiome: ten principles of holobionts and hologenomes. PLoS Biol 13:e1002226

Breviglieri CPB, Romero GQ (2019) Acoustic stimuli from predators trigger behavioural responses in aggregate caterpillars. Aust Ecol 44:880-890

Broderick NA, Raffa KF, Goodman RM, Handelsman J (2004) Census of the bacterial community of the gypsy moth larval midgut by using culturing and culture-independent methods. Appl Environ Microbiol 70:293-300

Brooks R, Hunt J, Blows MW, Smith MJ, Bussière LF, Jennions MD (2005) Experimental evidence for multivariate stabilizing sexual selection. Evolution 59:871-880

Cappuccino N (1992) Adjacent trophic-level effects on spatial density dependence in a herbivore-predator-parasitoid system. Ecol Entomol 17:105-108

Chen B, Teh B-S, Sun C, Hu S, Lu X, Boland W, Shao Y (2016) Biodiversity and activity of the gut microbiota across the life history of the insect herbivore Spodoptera littoralis. Sci Rep 6:29505

Clark BR, Faeth SH (1997) The consequences of larval aggregation in the butterfly Chlosyne lacinia. Ecol Entomol 22:408-415

Clark KE, Hartley SE, Johnson SN (2011) Does mother know best? The preference-performance hypothesis and parent-offspring conflict in aboveground-belowground herbivore life cycles. Ecol Entomol 36:117-124

Cole WE (1973) Crowding effects among single-age larvae of the mountain pine beetle, Dendroctonus ponderosae (Coleoptera: Scolytidae). Environ Entomol 2:285-293

Colman DR, Toolson EC, Takacs-Vesbach C (2012) Do diet and taxonomy influence insect gut bacterial communities? Mol Ecol 21:5124-5137

Colombani J, Andersen DS (2020) The Drosophila gut: A gatekeeper and coordinator of organism fitness and physiology. Wiley Interdiscip Rev Dev Biol. 16:e378. https://doi.org/10.1002/wdev.378

Connat JL, Delbecque JP, Glitho I, Delachambre J (1991) The onset of metamorphosis in Tenebrio molitor larvae (Insecta, Coleoptera) under grouped, isolated and starved conditions. J Insect Physiol 37:653-662

Consuegra J, Grenier T, Akherraz H, Rahioui I, Gervais H, da Silva P, Leulier F (2020) Metabolic cooperation among commensal bacteria supports Drosophila juvenile growth under nutritional stress. bioRxiv 2020.2005.2027.119370

Coon KL, Vogel KJ, Brown MR, Strand MR (2014) Mosquitoes rely on their gut microbiota for development. Mol Ecol 23:2727-2739

Correa MA, Brackney DE, Steven B (2018) Axenic Aedes aegypti develop without live bacteria, but exhibit delayed development and reduced oviposition. bioRxiv, 264978

Cotter SC, Hails RS, Cory JS, Wilson K (2004) Density-dependent prophylaxis and condition-dependent immune function in Lepidopteran larvae: a multivariate approach. J Anim Ecol 73:283-293

Couret J, Dotson E, Benedict MQ (2014) Temperature, larval diet, and density effects on development rate and survival of Aedes aegypti (Diptera: Culicidae). PLoS ONE 9:e87468

Creland PF, Dick KM, Wright AW (1986) Relationships between larval density, adult size and egg production in the cowpea seed beetle, Callosobruchus maculatus. Ecol Entomol 11:41-50

Crespi BJ (1989) Causes of assortative mating in arthropods. Anim Behav 38:980-1000

Criscuolo F, Monaghan P, Nasir L, Metcalfe NB (2008) Early nutrition and phenotypic development: 'catchup' growth leads to elevated metabolic rate in adulthood. Proc R Soc B Biol Sci 275:1565-1570

Dai X, Xu J, Guo Q, Lai S, Liu P, Fan J, Tang P (2019) Density effect and intraspecific competition in a leaf-mining moth on bamboo leaves. J For Res 30:689-697 
Davis TJ, Kline DL, Kaufman PE (2016) Assessment of Aedes albopictus (Skuse)(Diptera: Culicidae) clutch size in wild and laboratory populations. J Vector Ecol 41:11-17

Denno R, Benrey B (1997) Aggregation facilitates larval growth in the neotropical nymphalid butterfly Chlosyne janais. Ecol Entomol 22:133-141

Dethier VG (1959) Food-plant distribution and density and larval dispersal as factors affecting insect populations. Can Entomol 91:581-596

Dey S, Joshi A (2018) Two decades of drosophila population dynamics: modeling, experiments, and implications. In: Srinivasa Rao ASR, Rao CR (eds) Handbook of statistics. Elsevier, Amsterdam, pp 275-312

Diamantidis AD, Ioannou CS, Nakas CT, Carey JR, Papadopoulos NT (2019) Differential response to larval crowding of a long- and a short-lived medfly biotype. J Evol Biol 00:1-13

Douglas AE (2009) The microbial dimension in insect nutritional ecology. Funct Ecol 23:38-47

Douglas AE (2015) Multiorganismal insects: diversity and function of resident microorganisms. Annu Rev Entomol 60:17-34

Douglas AE (2019) Simple animal models for microbiome research. Nat Rev Microbiol 17:764-775

Drew RAI, Courtice AC, Teakle DS (1983) Bacteria as a natural source of food for adult fruit flies (Diptera: Tephritidae). Oecologia 60:279-284

Dukas R, Prokopy RJ, Duan JJ (2001) Effects of larval competition on survival and growth in Mediterranean fruit flies. Ecol Entomol 26:587-593

Edelaar P, Bolnick DI (2019) Appreciating the multiple processes increasing individual or population fitness. Trends Ecol Evol 34:435-446

Fantinou AA, Perdikis DC, Stamogiannis N (2008) Effect of larval crowding on the life history traits of Sesamia nonagrioides (Lepidoptera: Noctuidae). Eur J Entomol 105:625-630

Gage MJ (1995) Continuous variation in reproductive strategy as an adaptive response to population density in the moth Plodia interpunctella. Proc R Soc Lond Ser B Biol Sci 261:25-30

García-Robledo C, Horvitz CC (2012) Parent-offspring conflicts, "optimal bad motherhood" and the "mother knows best" principles in insect herbivores colonizing novel host plants. Ecol Evol 2:1446-1457

Genta FA, Dillon RJ, Terra WR, Ferreira C (2006) Potential role for gut microbiota in cell wall digestion and glucoside detoxification in Tenebrio molitor larvae. J Insect Physiol 52:593-601

Gibbs M, Lace LA, Jones MJ, Moore AJ (2004) Intraspecific competition in the speckled wood butterfly Pararge aegeria: effect of rearing density and gender on larval life history. J Insect Sci 4:16

Gibson AM, Bratchell N, Roberts TA (1988) Predicting microbial growth: growth responses of salmonellae in a laboratory medium as affected by $\mathrm{pH}$, sodium chloride and storage temperature. Int $\mathrm{J}$ Food Microbiol 6:155-178

Gimnig JE, Ombok M, Otieno S, Kaufman MG, Vulule JM, Walker ED (2002) Density-dependent development of Anopheles gambiae (Diptera: Culicidae) larvae in artificial habitats. J Med Entomol 39:162-172

Glass LW, Bovbjerg RV (1969) Density and dispersion in laboratory populations of caddisfly larvae (Cheumatopsyche, Hydropsychidae). Ecology 50:1082-1084

Gonzalez-Ceron L, Santillan F, Rodriguez MH, Mendez D, Hernandez-Avila JE (2003) Bacteria in midguts of field-collected Anopheles albimanus block Plasmodium vivax sporogonic development. J Med Entomol 40:371-374

Green P, Simmonds M, Blaney WM (2002) Diet nutriment and rearing density affect the growth of black blowfly larvae, Phormia regina (Meigen) (Diptera: Calliphoridae). Eur J Entomol 100:39-42

Hassell M, May R (1986) Generalist and specialist natural enemies in insect predator-prey interactions. J Anim Ecol 55:923-940

Hawley W (1985) The effect of larval density on adult longevity of a mosquito, Aedes sierrensis: epidemiological consequences. J Anim Ecol 955-964

He Y, Miyata T (1997) Variations in sperm number in relation to larval crowding and spermatophore size in the armyworm, Pseudaletia separata. Ecol Entomol 22:41-46

Henriques SF, Serra L, Francisco AP, Carvalho-Santos Z, Baltazar C, Elias AP, Anjos M, Zhang T, Maddocks ODK, Ribeiro C (2019) Metabolic cross-feeding allows a gut microbial community to overcome detrimental diets and alter host behaviour. bioRxiv 821892

Henry Y, Renault D, Colinet H (2018) Hormesis-like effect of mild larval crowding on thermotolerance in Drosophila flies. J Exp Biol 221:jeb169342

Henry Y, Tarapacki P, Colinet H (2020) Larval density affects phenotype and surrounding bacterial community without altering gut microbiota in Drosophila melanogaster. FEMS Microbiol Ecol 96

Herren JK, Paredes JC, Schüpfer F, Lemaitre B (2013) Vertical transmission of a Drosophila endosymbiont via cooption of the yolk transport and internalization machinery. mBio 4:e00532-00512 
Hunt J, Blows MW, Zajitschek F, Jennions MD, Brooks R (2007) Reconciling strong stabilizing selection with the maintenance of genetic variation in a natural population of black field crickets (Teleogryllus commodus). Genetics 177:875-880

Ikeshoji T, Mullai MS (1970) Overcrowding factors of mosquito larvae. J Econ Entomol 63:90-96

Inouye BD, Johnson DM (2005) Larval aggregation affects feeding rate in Chlosyne poecile (Lepidoptera: Nymphalidae). Florida Entomologist 88:247-252

Ireland S, Turner B (2006) The effects of larval crowding and food type on the size and development of the blowfly, Calliphora vomitoria. For Sci Int 159:175-181

Jannat KN, Roitberg BD (2013) Effects of larval density and feeding rates on larval life history traits in Anopheles gambiae s.s. (Diptera: Culicidae). J Vector Ecol 38:120-126

Jiang Y, Bolnick DI, Kirkpatrick M (2013) Assortative mating in animals. Am Nat 181:E125-E138

Jiang L, Cheng Y, Gao S, Zhong Y, Ma C, Wang T, Zhu Y (2020) Emergence of social cluster by collective pairwise encounters in Drosophila. eLife 9:e51921

Jing T-Z, Qi F-H, Wang Z-Y (2020) Most dominant roles of insect gut bacteria: digestion, detoxification, or essential nutrient provision? Microbiome 8:38

Johnson T, Barton N (2005) Theoretical models of selection and mutation on quantitative traits. Philos Trans R Soc B Biol Sci 360:1411-1425

Johnson TL, Symonds MRE, Elgar MA (2017) Anticipatory flexibility: larval population density in moths determines male investment in antennae, wings and testes. Proc Royal Soc B Biol Sci 284:20172087

Johnston PR, Rolff J (2015) Host and symbiont jointly control gut microbiota during complete metamorphosis. PLoS Pathog 11:e1005246

Jose PA, Ben-Yosef M, Jurkevitch E, Yuval B (2019) Symbiotic bacteria affect oviposition behavior in the olive fruit fly Bactrocera oleae. J Insect Physiol 117:103917

Joshi A, Mueller LD (1996) Density-dependent natural selection inDrosophila: trade-offs between larval food acquisition and utilization. Evol Ecol 10:463-474

Joshi A, Prasad N, Shakarad M (2001) K-selection, $\alpha$-selection, effectiveness, and tolerance in competition: density-dependent selection revisited. J Genet 80:63-75

Kaznowski A, Szymas B, Jazdzinska E, Kazimierczak M, Paetz H, Mokracka J (2005) The effects of probiotic supplementation on the content of intestinal microflora and chemical composition of worker honey bees (Apis mellifera). J Apic Res 44:10-14

Kivelä SM, Välimäki P (2008) Competition between larvae in a butterfly Pieris napi and maintenance of different life-history strategies. J Anim Ecol 77:529-539

Klepsatel P, Prochazka E, Gáliková M (2018) Crowding of Drosophila larvae affects lifespan and other life-history traits via reduced availability of dietary yeast. Exp Gerontol 110:298-308

Kunin WE (2019) Robust evidence of declines in insect abundance and biodiversity. Nature 574:641-642

Kuno E (1962) The effect of population density on the reproduction of Trichogramma japonicum Ashmead (Hymenoptera: Trichogrammatidae). Popul Ecol 4:47-59

Lawrence D, Fiegna F, Behrends V, Bundy JG, Phillimore AB, Bell T, Barraclough TG (2012) Species interactions alter evolutionary responses to a novel environment. PLoS Biol 10:e1001330

Lazarevic J, Peric-Mataruga V, Vlahovic M, Mrdakovic M, Cvetanovic D (2004) Effects of rearing density on larval growth and activity of digestive enzymes in Lymantria dispar L. (Lepidoptera: Lymantriidae). Folia Biol-krakow 52:105-112

Leftwich PT, Clarke NV, Hutchings MI, Chapman T (2017) Gut microbiomes and reproductive isolation in Drosophila. Proc Natl Acad Sci 114:12767-12772

Lesperance DNA, Broderick NA (2020) Microbiomes as modulators of Drosophila melanogaster homeostasis and disease. Curr Opin Insect Sci 39:84-90

Lewis Z, Lizé A (2015) Insect behaviour and the microbiome. Curr Opin Insect Sci 9:86-90

Lindström J (1999) Early development and fitness in birds and mammals. Trends Ecol Evol 14:343-348

Liu W-C, Bonsall M, Godfray H (2007) The form of host density-dependence and the likelihood of hostpathogen cycles in forest-insect systems. Theor Popul Biol 72:86-95

Lushchak OV, Karaman HS, Kozeretska IA, Koliada AK, Zabuga OG, Pisaruk AV, Koshel NM, Mechova LV, Inomistova MV, Khranovska NM, Vaiserman AM (2019) Larval crowding results in hormesis-like effects on longevity in Drosophila: timing of eclosion as a model. Biogerontology 20:191-201

Ma D, Bou-Sleiman M, Joncour P, Indelicato C-E, Frochaux M, Braman V, Litovchenko M, Storelli G, Deplancke B, Leulier F (2019) Commensal gut bacteria buffer the impact of host genetic variants on Drosophila developmental traits under nutritional stress. iScience 19:436-447

Maciá A (2017) Effects of larval crowding on development time, survival and weight at metamorphosis in Aedes aegypti (Diptera: Culicidae). Rev de la Soc Entomol Argent 68:107-114 
Manorenjitha MS, Zairi J (2012) Nutrition and overcrowding effects on larval development and fecundity of female Aedes albopictus (Skuse). Int J Life Sci Med Res 2:63-67

May R, Hassell M, Anderson R, Tonkyn D (1981) Density dependence in host-parasitoid models. J Anim Ecol 50:855-865

McGraw LA, Fiumera AC, Ramakrishnan M, Madhavarapu S, Clark AG, Wolfner MF (2007) Larval rearing environment affects several post-copulatory traits in Drosophila melanogaster. Biol Let 3:607-610

McNamara KB, Simmons LW (2017) Experimental evolution reveals differences between phenotypic and evolutionary responses to population density. J Evol Biol 30:1763-1771

Milonas PG (2005) Influence of initial egg density and host size on the development of the gregarious parasitoid Bracon hebetor on three different host species. Biocontrol 50:415

Mirth C, Truman JW, Riddiford LM (2005) The role of the prothoracic gland in determining critical weight for metamorphosis in Drosophila melanogaster. Curr Biol 15:1796-1807

Monaghan P (2008) Early growth conditions, phenotypic development and environmental change. Philos Trans R Soc B Biol Sci 363:1635-1645

Morimoto J, Pizzari T, Wigby S (2016) Developmental environment effects on sexual selection in male and female Drosophila melanogaster. PLoS ONE 11:e0154468

Morimoto J, Ponton F, Tychsen I, Cassar J, Wigby S (2017a) Interactions between the developmental and adult social environments mediate group dynamics and offspring traits in Drosophila melanogaster. Sci Rep 7:3574

Morimoto J, Simpson SJ, Ponton F (2017) Direct and trans-generational effects of male and female gut microbiota in Drosophila melanogaster. Biol Lett 13:20160966.

Morimoto J, Nguyen B, Tabrizi ST, Ponton F, Taylor P (2018) Social and nutritional factors shape larval aggregation, foraging, and body mass in a polyphagous fly. Sci Rep 8:14750

Morimoto J, Nguyen B, Dinh H, Than A, Taylor PW, Ponton F (2019a) Crowded developmental environment promotes adult sex-specific nutrient consumption in a polyphagous fly. Front Zool 16:4

Morimoto J, Nguyen B, Tabrizi ST, Lundbäck I, Taylor PW, Ponton F, Chapman TA (2019b) Commensal microbiota modulates larval foraging behaviour, development rate and pupal production in Bactrocera tryoni. BMC Microbiol 19:286

Mueller LD (1990) Density-dependent natural selection does not increase efficiency. Evol Ecol 4:290-297

Mueller LD (1997) Theoretical and empirical examination of density-dependent selection. Annu Rev Ecol Syst 28:269-288

Mueller LD, Ayala FJ (1981) Trade-off between r-selection and K-selection in Drosophila populations. Proc Natl Acad Sci USA 78:1303-1305

Mueller LD, Guo PZ, Ayala FJ (1991) Density-dependent natural selection and trade-offs in life history traits. Science 253:433-435

Mueller L, Graves J Jr, Rose M (1993) Interactions between density-dependent and age-specific selection in Drosophila melanogaster. Funct Ecol 7:469

Muriu SM, Coulson T, Mbogo CM, Godfray HCJ (2013) Larval density dependence in Anopheles gambiae ss, the major African vector of malaria. J Anim Ecol 82:166

Nagarajan A, Natarajan SB, Jayaram M, Thammanna A, Chari S, Bose J, Jois SV, Joshi A (2016) Adaptation to larval crowding in Drosophila ananassae and Drosophila nasuta nasuta: increased larval competitive ability without increased larval feeding rate. J Genet 95:411-425

Nahrung HF, Dunstan PK, Allen GR (2001) Larval gregariousness and neonate establishment of the eucalypt-feeding beetle Chrysophtharta agricola (Coleoptera: Chrysomelidae: Paropsini). Oikos 94:358-364

Newton IL, Sheehan KB, Lee FJ, Horton MA, Hicks RD (2013) Invertebrate systems for hypothesis-driven microbiome research. Microb Sci Med 1:1-9

Nguyen B, Ponton F, Than A, Taylor PW, Chapman T, Morimoto J (2019) Interactions between ecological factors in the developmental environment modulate pupal and adult traits in a polyphagous fly. Ecol Evol 9:6342-6352

Nijhout HF (2015) A developmental-physiological perspective on the development and evolution of phenotypic plasticity, vol 307. Conceptual change in biology, Springer. pp 147-173

Ower GD, Juliano SA (2019) Effects of larval density on a natural population of Culex restuans (Diptera: Culicidae): no evidence of compensatory mortality. Ecol Entomol 44:197-205

Pearl R, Miner JR, Parker SL (1927) Experimental studies on the duration of life. XI. Density of population and life duration in Drosophila. Am Nat 61:289-318

Peck GW, Walton WE (2006) Effect of bacterial quality and density on growth and whole body stoichiometry of Culex quinquefasciatus and Culex tarsalis (Diptera: Culicidae). J Med Entomol 43:25-33

Pétavy G, Morin J, Moreteau B, David J (1997) Growth temperature and phenotypic plasticity in two Drosophila sibling species: probable adaptive changes in flight capacities. J Evol Biol 10:875-887 
Piesk M, Karl I, Franke K, Fischer K (2013) High larval density does not induce a prophylactic immune response in a butterfly. Ecol Entomol 38:346-354

Prasad NG, Joshi A (2003) What have two decades of laboratory life-history evolution studies on Drosophila melanogaster taught us? J Genet 82:45-76

Prasad N, Shakarad M, Anitha D, Rajamani M, Joshi A (2001) Correlated responses to selection for faster development and early reproduction in Drosophila: the evolution of larval traits. Evolution 55:1363-1372

Quennedey A, Aribi N, Everaerts C, Delbecque J-P (1995) Postembryonic development of Zophobas atratus Fab. (Coleoptera: Tenebrionidae) under crowded or isolated conditions and effects of juvenile hormone analogue applications. J Insect Physiol 41:143-152

Rada S, Schweiger O, Harpke A, Kühn E, Kuras T, Settele J, Musche M (2019) Protected areas do not mitigate biodiversity declines: a case study on butterflies. Divers Distrib 25:217-224

Reilly JR, Hajek AE (2007) Density-dependent resistance of the gypsy moth Lymantria dispar to its nucleopolyhedrovirus, and the consequences for population dynamics. Oecologia 154:691-701

Reis SFS, Von Zuben CJ, Godoy WAC (1999) Larval aggregation and competition for food in experimental populations of Chrysomya putoria (Wied.) and Cochliomyia macellaria (F.) (Dipt., Calliphoridae). J Appl Entomol 123:485-489

Reiskind M, Lounibos L (2009) Effects of intraspecific larval competition on adult longevity in the mosquitoes Aedes aegypti and Aedes albopictus. Med Vet Entomol 23:62-68

Roberts D (1998) Overcrowding of Culex sitiens (Diptera: Culicidae) larvae: population regulation by chemical factors or mechanical interference. J Med Entomol 35:665-669

Rooke R, Rasool A, Schneider J, Levine JD (2020) Drosophila melanogaster behaviour changes in different social environments based on group size and density. Commun Biol 3:304

Roper C, Pignatelli P, Partridge L (1996) Evolutionary responses of Drosophila melanogaster life history to differences in larval density. J Evol Biol 9:609-622

Rousk J, Brookes PC, Bååth E (2009) Contrasting soil pH effects on fungal and bacterial growth suggest functional redundancy in carbon mineralization. Appl Environ Microbiol 75:1589-1596

Russell JB, Dombrowski DB (1980) Effect of pH on the efficiency of growth by pure cultures of rumen bacteria in continuous culture. Appl Environ Microbiol 39:604-610

Salem H, Bauer E, Strauss AS, Vogel H, Marz M, Kaltenpoth M (2014) Vitamin supplementation by gut symbionts ensures metabolic homeostasis in an insect host. Proc R Soc B Biol Sci 281:20141838

Sannino DR, Dobson AJ, Edwards K, Angert ER, Buchon N (2018) The Drosophila melanogaster gut microbiota provisions thiamine to its host. MBio 9:e00155-00118

Saunders D, Bee A (2013) Effects of larval crowding on size and fecundity of the blow fly, Calliphora vicina (Diptera: Calliphoridae). EJE 92:615-622

Saunders DS, Wheeler I, Kerr A (1999) Survival and reproduction of small blow flies (Calliphora vicina; Diptera: Calliphoridae) produced in severely overcrowded short-day larval cultures. EJE 96:19-22

Savvidou N, Bell CH (1994) The effect of larval density, photoperiod and food change on the development of Gnatocerus cornutus (F.)(Coleoptera: Tenebrionidae). J Stored Prod Res 30:17-21

Schenk D, Bacher S (2002) Functional response of a generalist insect predator to one of its prey species in the field. J Anim Ecol 71:524-531

Schou TM, Faurby S, Kjaersgaar A, Pertoldi C, Loeschcke V, Hald B, Bahrndorff S (2013) Temperature and population density effects on locomotor activity of Musca domestica (Diptera: Muscidae). Environ entomol 42:1322-1328

Schrader M, Jarrett BJ, Kilner RM (2015) Parental care masks a density-dependent shift from cooperation to competition among burying beetle larvae. Evolution 69:1077-1084

Schretter CE, Vielmetter J, Bartos I, Marka Z, Marka S, Argade S, Mazmanian SK (2018) A gut microbial factor modulates locomotor behaviour in Drosophila. Nature 563:402-406

Sharon G, Segal D, Zilber-Rosenberg I, Rosenberg E (2011) Symbiotic bacteria are responsible for dietinduced mating preference in Drosophila melanogaster, providing support for the hologenome concept of evolution. Gut Microbes 2:190-192

Shenoi VN, Ali SZ, Prasad NG (2016a) Evolution of increased adult longevity in Drosophila melanogaster populations selected for adaptation to larval crowding. J Evol Biol 29:407-417

Shenoi VN, Banerjee SM, Guruswamy B, Sen S, Ali SZ, Prasad NG (2016b) Drosophila melanogaster males evolve increased courtship as a correlated response to larval crowding. Anim Behav 120:183-193

Shin SC, Kim S-H, You H, Kim B, Kim AC, Lee K-A, Yoon J-H, Ryu J-H, Lee W-J (2011) Drosophila microbiome modulates host developmental and metabolic homeostasis via insulin signaling. Science 334:670-674 
Shine R, Brown GP, Phillips BL (2011) An evolutionary process that assembles phenotypes through space rather than through time. Proc Natl Acad Sci 108:5708-5711

Silberglied RE, Shepherd JG, Dickinson JL (1984) Eunuchs: the role of apyrene sperm in Lepidoptera? Am Nat 123:255-265

Smallegange IM, Tregenza T (2008) Local competition between foraging relatives: growth and survival of Bruchid beetle larvae. J insect Behav 21:375-386

Sokolowski MB, Pereira HS, Hughes K (1997) Evolution of foraging behavior in Drosophila by densitydependent selection. Proc Natl Acad Sci 94:7373-7377

Sommer AJ, Newell PD (2019) Metabolic basis for mutualism between gut bacteria and its impact on the Drosophila melanogaster host. Appl Environ Microbiol 85:e1882-01818

Stamps JA (2006) The silver spoon effect and habitat selection by natal dispersers. Ecol Lett 9:1179-1185

Stearns S (1982) The role of development in the evolution of life histories. Evolution and development, vol 22. Springer. pp 237-258.

Stiling P (1988) Density-dependent processes and key factors in insect populations. J Anim Ecol 57:581-593

Storelli G, Defaye A, Erkosar B, Hols P, Royet J, Leulier F (2011) Lactobacillus plantarum promotes Drosophila systemic growth by modulating hormonal signals through TOR-dependent nutrient sensing. Cell Metab 14:403-414

Storelli G, Strigini M, Grenier T, Bozonnet L, Schwarzer M, Daniel C, Matos R, Leulier F (2018) Drosophila perpetuates nutritional mutualism by promoting the fitness of its intestinal symbiont Lactobacillus plantarum. Cell Metab 27:362-377.e368

Tang X, Freitak D, Vogel H, Ping L, Shao Y, Cordero EA, Andersen G, Westermann M, Heckel DG, Boland W (2012) Complexity and variability of gut commensal microbiota in polyphagous lepidopteran larvae. PLoS ONE 7:e36978

Taylor AD (1988) Host effects on larval competition in the gregarious parasitoid Bracon hebetor. J Anim Ecol 57:163-172

Thomas R, Harwood J, Glen D, Symondson WOC (2009) Tracking predator density dependence and subterranean predation by carabid larvae on slugs using monoclonal antibodies. Ecol Entomol 34:569-579

Travis J (2020) Where is natural history in ecological, evolutionary, and behavioral science? Am Soc Nat 196:1-8

Trienens M, Keller NP, Rohlfs M (2010) Fruit, flies and filamentous fungi-experimental analysis of animal-microbe competition using Drosophila melanogaster and Aspergillus mould as a model system. Oikos 119:1765-1775

Truman JW (2019) The evolution of insect metamorphosis. Curr Biol 29:R1252-R1268

Tsuda Y, Yoshida T (1985) Population biology of the broad-horned flour beetle, Gnathocerus cornutus (F.) II. Crowding effects of larvae on their survival and development. Res Popul Ecol 27:77-85

Vacchini V, Gonella E, Crotti E, Prosdocimi EM, Mazzetto F, Chouaia B, Callegari M, Mapelli F, Mandrioli M, Alma A (2017) Bacterial diversity shift determined by different diets in the gut of the spotted wing fly Drosophila suzukii is primarily reflected on acetic acid bacteria. Environ Microbiol Rep 9:91-103

Välimäki P, Kivelä SM, Mäenpää MI (2013) Temperature-and density-dependence of diapause induction and its life history correlates in the geometrid moth Chiasmia clathrata (Lepidoptera: Geometridae). Evol Ecol 27:1217-1233

Vander Wal E, Webber QMR (2019) Density dependence and eco-evolutionary dynamics of animal social networks: a comment on Shizuka and Johnson. Behav Ecol 31:16-18

Vijendravarma RK, Narasimha S, Kawecki TJ (2013) Predatory cannibalism in Drosophila melanogaster larvae. Nat Commun 4:1-8

Wagner D (2019) Insect declines in the Anthropocene. Annu Rev Entomol 65:457-480

Warnecke F, Luginbühl P, Ivanova N, Ghassemian M, Richardson TH, Stege JT, Cayouette M, McHardy AC, Djordjevic G, Aboushadi N, Sorek R, Tringe SG, Podar M, Martin HG, Kunin V, Dalevi D, Madejska J, Kirton E, Platt D, Szeto E, Salamov A, Barry K, Mikhailova N, Kyrpides NC, Matson EG, Ottesen EA, Zhang X, Hernández M, Murillo C, Acosta LG, Rigoutsos I, Tamayo G, Green BD, Chang C, Rubin EM, Mathur EJ, Robertson DE, Hugenholtz P, Leadbetter JR (2007) Metagenomic and functional analysis of hindgut microbiota of a wood-feeding higher termite. Nature 450:560

Watanabe M (2016) Apyrene sperm as a key factor for sperm competition. Sperm Competition in Butterflies. Ecological Research Monographs, vol 1. Springer Japan, Tokyo. pp 157-167

Weaver DK, McFarlane J (1990) The effect of larval density on growth and development of Tenebrio molitor. J Insect Physiol 36:531-536

Welti EAR, Roeder KA, de Beurs KM, Joern A, Kaspari M (2020) Nutrient dilution and climate cycles underlie declines in a dominant insect herbivore. Proc Natl Acad Sci 117:7271-7275 
Wertheim B, Marchais J, Vet LEM, Dicke M (2002) Allee effect in larval resource exploitation in Drosophila: an interaction among density of adults, larvae, and micro-organisms. Ecol Entomol 27:608-617

Westfall S, Lomis N, Prakash S (2019) Ferulic acid produced by Lactobacillus fermentum influences developmental growth through a dTOR-Mediated mechanism. Mol Biotechnol 61:1-11

Wigby S, Perry JC, Kim YH, Sirot LK (2016) Developmental environment mediates male seminal protein investment in Drosophila melanogaster. Funct Ecol 30:410-419

Wilson K, Cotter S (2008) Density-dependent prophylaxis in insects. In: Ananthakrishnan TN, Whitman TW (eds) Phenotypic plasticity of insects: mechanisms and consequences, vol 1. Science Publishers, Enfield, UK. 381-420

Wilson K, Graham RI (2015) Transgenerational effects modulate density-dependent prophylactic resistance to viral infection in a lepidopteran pest. Biol Let 11:20150012

Wilson RJ, Maclean IMD (2011) Recent evidence for the climate change threat to Lepidoptera and other insects. J Insect Conserv 15:259-268

Wong AC, Wang QP, Morimoto J, Senior AM, Lihoreau M, Neely GG, Simpson SJ, Ponton F (2017) Gut microbiota modifies olfactory-guided microbial preferences and foraging decisions in Drosophila. Curr Biol 27:2397-2404.e2394

Yang AS (2001) Modularity, evolvability, and adaptive radiations: a comparison of the hemi- and holometabolous insects. Evol Dev 3:59-72

Yun J-H, Roh SW, Whon TW, Jung M-J, Kim M-S, Park D-S, Yoon C, Nam Y-D, Kim Y-J, Choi J-H (2014) Insect gut bacterial diversity determined by environmental habitat, diet, developmental stage, and phylogeny of host. Appl Environ Microbiol 80:5254-5264

Zaada DSY, Ben-Yosef M, Yuval B, Jurkevitch E (2019) The host fruit amplifies mutualistic interaction between Ceratitis capitata larvae and associated bacteria. BMC Biotechnol 19:92

Zhang Z, Jiao S, Li X, Li M (2018) Bacterial and fungal gut communities of Agrilus mali at different developmental stages and fed different diets. Sci Rep 8:15634

Zhao Y, Wang W, Zhu F, Wang X, Wang X, Lei C (2017) The gut microbiota in larvae of the housefly Musca domestica and their horizontal transfer through feeding. AMB Express 7:147

Zhou X, Smith JA, Oi FM, Koehler PG, Bennett GW, Scharf ME (2007) Correlation of cellulase gene expression and cellulolytic activity throughout the gut of the termite Reticulitermes flavipes. Gene 395:29-39

Zwaan B, Bijlsma R, Hoekstra R (1991) On the developmental theory of ageing. I. Starvation resistance and longevity in Drosophila melanogaster in relation to pre-adult breeding conditions. Heredity 66:29

Publisher's Note Springer Nature remains neutral with regard to jurisdictional claims in published maps and institutional affiliations. 